\title{
Effect of the $I \kappa B \alpha$ mutant gene delivery to mesenchymal stem cells on rat chronic pancreatitis
}

T. Qin ${ }^{1 *}$, C.J. Liu ${ }^{1 *}$, H.W. Zhang ${ }^{1}$, Y.F. Pan ${ }^{2}$, Q. Tang ${ }^{1}$, J.K. Liu 1 Y.Z. Wang ${ }^{1}$, M.X. Hu${ }^{1}$ and F. Xue ${ }^{1}$

${ }^{1}$ Department of Hepatobiliary Pancreatic Surgery, Henan People’s Hospital, Zhengzhou, Henan Province, China

${ }^{2}$ Department of Infection Disease, The First Affiliated Hospital of Zhengzhou University, Zhengzhou, Henan Province, China

*These authors contributed equally to this study. Corresponding author: H.W. Zhang

E-mail: hongweizhangcn@163.com

Genet. Mol. Res. 13 (1): 371-385 (2014)

Received August 8, 2013

Accepted October 26, 2013

Published January 21, 2014

DOI http://dx.doi.org/10.4238/2014.January.21.5

\begin{abstract}
This study aimed to investigate the effect of inhibitors of the NF- $\kappa B$ alpha mutant gene (I $\mathrm{B} \alpha \mathrm{M})$ delivery to mensenchymal stem cells (MSCs) on rat chronic pancreatitis (CP). A total of 120 SpragueDawley rats were randomly divided into 6 groups of 20: Group A was injected with sterile saline solution, Group B was injected with allogenic MSCs, Group C1 was injected with allogenic IкB $\alpha M-M S C s$ cultured in vitro $4 \mathrm{~h}$ before $\mathrm{CP}$ modeling, Group $\mathrm{C} 2$ was injected with allogenic I $\kappa \mathrm{B} \alpha \mathrm{M}-\mathrm{MSC}$ s cultured in vitro during $\mathrm{CP}$ modeling, Group $\mathrm{C} 3$ was cultured with allogenic IкB $\alpha \mathrm{M}-\mathrm{MSCs}$ cultured in vitro $4 \mathrm{~h}$ after $\mathrm{CP}$ modeling, and Group D was injected with rAAV2-MSCs. Cytokine levels of ICAM-1, CTGF, IL-1, IL-6, IL-8, TNF- $\alpha$, TIMP-1, TIMP2, IL-10, FN, MMP-1, MMP-2, MMP-3, and MMP-9 were examined. The results indicated that allogenic IкB $\alpha \mathrm{M}-\mathrm{MSCs}$ could reduce pro-
\end{abstract}


inflammatory cytokine levels and increase anti-inflammatory cytokine levels in CP. The allogenic IкB $\alpha \mathrm{M}-\mathrm{MSC}$ s reduced the activation and promoted the apoptosis of pancreatic stellate cells in the rat model of CP. I $\mathrm{B} \alpha \mathrm{M}-\mathrm{MSCs}$ influenced the proliferation and apoptosis of pancreatic stellate cells by regulating the activation of the PPAR, MAPK, mTOR, TGF- $\beta$, NOD-like receptor, Notch, WNT, TGF- $\beta 1$-SMAD- $2 / 3$, and P53 signal transduction pathways.

Key words: I $\mathrm{B} \alpha \mathrm{M}$; Chronic pancreatitis; Pancreatic stellate cell; Inflammatory factors; Co-cultured; Gene sequence

\section{INTRODUCTION}

In chronic pancreatitis (CP), the accumulation of extracellular matrix (ECM) causes development of pancreatic fibrosis, which results in exocrine and endocrine pancreatic insufficiency (Apte et al., 1998; Bachem et al., 1998; Phillips, 2012). Fibrosis is a potential risk factor of pancreatic cancer and may play an active role in disease progression (Haber et al., 1999). Despite significant efforts in recent years, effective therapies to inhibit or even reverse pancreatic fibrosis remain elusive.

Pancreatic stellate cells (PSCs) have recently been identified and characterized (Apte et al., 1998). Similar to hepatic stellate cells, PSCs also play key roles in pancreatic fibrosis, inflammation, and desmoplastic reactions in CP. In the normal pancreas, PSCs possessing fat droplets with vitamin A are quiescent. In the quiescent state, they are characterized by desminpositive and $\alpha$-smooth muscle actin ( $\alpha$-SMA)-negative staining (Apte et al., 1998). When cultured in vitro, the auto-activation or auto-transformation of PSCs changes their morphological and functional features (Bachem et al., 1998). PSCs start losing lipid droplets with vitamin A, show high proliferation, increased expression of $\alpha$-SMA, and secretion of ECM components, such as collagen and fibronectin (FN). PSCs auto-transform to myofibroblast-like cells. PSCs are also activated during pancreatic fibrosis in vivo (Haber et al., 1999).

PSCs are therefore the main effector cells involved in pancreatic fibrosis (Omary et al., 2007; Phillips, 2012). Following liver damage in CP, acinar, duct, endothelial, and inflammatory cells all release a large amount of inflammatory mediators, such as platelet-derived growth factor, transforming growth factor-beta (TGF- $\beta$ ), interleukin-1 (IL-1), tumor necrosis factor-alpha (TNF- $\alpha$ ), and so on, resulting in PSC activation, aggregation, and proliferation (Apte et al., 1999; Aoki et al., 2006; Habisch et al., 2010). Finally, the cell morphology and function of PSCs are changed and self-activated to promote matrix proliferation (Apte et al., 1998, 1999; Phillips et al., 2003). A large amount of collagen is produced and deposited, eventually leading to the development of pancreatic fibrosis (Ellenrieder et al., 2004). Thus, activated PSCs are believed to play a central role in pancreatic fibrosis and are considered to be a promising target for anti-fibrotic therapies.

Nuclear factor-kappa B (NF-kB) is an important transcription factor that regulates

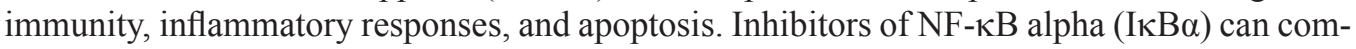
bine with NF- $\kappa B$ to keep it in an inactive state in the cytoplasm. TNF- $\alpha$ and IL-1 transduce signals to NF- $\kappa \mathrm{B}$ inducing kinase (NIK) by binding to receptors. This in turn activates the IкB kinase (IKK) to induce the phosphorylation of Ser32 and Ser36 of IкB $\alpha$. Subsequently, IкB $\alpha$

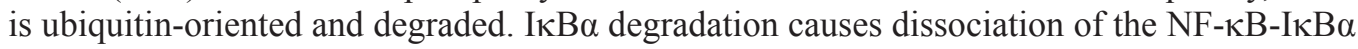


complex. Finally, free NF- $\kappa \mathrm{B}$ dimers migrate to the nucleus and induce the expression of related genes (Ghosh et al., 1998). When Ser32 and Ser36 are replaced with valine residues, $\mathrm{I} \kappa \mathrm{B} \alpha$ mutant $(\mathrm{I} \kappa \mathrm{B} \alpha \mathrm{M})$ retains its binding activity to NF- $\kappa \mathrm{B}$, and phosphorylation and degradation are inhibited, which prevents NF- $\kappa \mathrm{B}$ activation.

We constructed an IкB $\alpha M$ using valine residues instead of Ser32 and Ser36 to further block NF- $\mathrm{BB}$ activation in cells. In this study, we injected mensenchymal stell cells (MSCs)

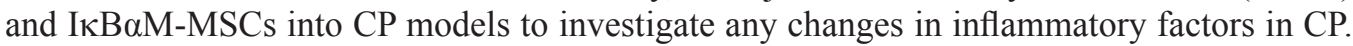
The GeneChip Rat Genome 2302.0 array was used to investigate changes in PSC gene se-

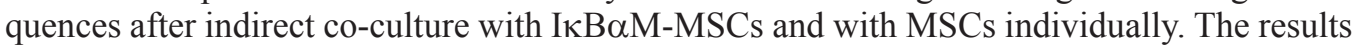
of this study provide evidence for the development of therapeutic strategies for CP.

\section{MATERIAL AND METHODS}

\section{Experimental groupings}

A total of 120 Sprague-Dawley (SD) rats were randomly divided into 6 groups of 20: Group A was injected with sterile saline, Group B was injected with allogeneic MSCs cultured in vitro, Group $\mathrm{C} 1$ was injected with allogeneic I $\mathrm{B} \alpha \mathrm{M}-\mathrm{MSCs}$ cultured in vitro $4 \mathrm{~h}$ before $\mathrm{CP}$ modeling, Group $\mathrm{C} 2$ was injected with allogeneic IкB $\alpha \mathrm{M}-\mathrm{MSCs}$ cultured in vitro $4 \mathrm{~h}$ after $\mathrm{CP}$ modeling, Group $\mathrm{C} 3$ was injected with allogeneic IкB $\alpha \mathrm{M}-\mathrm{MSC}$ s cultured in vitro during $\mathrm{CP}$ modeling, and Group D was injected with rAAV2-MSCs.

PSCs were added to the lower layer of a Transwell system that was pre-cultured with fifth-generation MSCs, rAAV2-MSCs, and IкB $\alpha$ M-MSCs.

Disposal of animals during experimental procedures was performed in accordance with the guidelines and standards of treating experimental animals promulgated by The Ministry of Science and Technology of the People's Republic of China (2006).

\section{Isolation, culture, and identification of rat bone marrow MSCs and PSC cultivation}

SD rats weighing approximately 150-200 g were injected intraperitoneally with $3 \mathrm{~mL} /$ $\mathrm{kg} 10 \%$ chloral hydrate as anesthesia. Under sterile conditions, both ends of the rat femoral and tibial bones were cut off. Complete medium was used to flush the bone marrow cavity. After full winding and percussion mixing, large clumps were removed via lavage with a 74$\mu \mathrm{m}$ stainless steel standard sieve. The medium was placed in $25-\mathrm{cm}^{2}$ culture flasks and was then incubated at $37^{\circ} \mathrm{C}$ in a $5 \%$ carbon dioxide $\left(\mathrm{CO}_{2}\right)$ atmosphere. The medium was changed after $48 \mathrm{~h}$ and then every 3 days thereafter. After $80-90 \%$ cells merged and formed a monolayer culture at the bottom of flasks, $0.25 \%$ trypsin was used for subculture. After MSCs were cultured to the fifth generation, $0.25 \%$ trypsin was used for passage. MSCs were washed twice with phosphate-buffered saline to a concentration of $2 \times 10^{9} / \mathrm{L}$ suspension, and were then filtered using a $48-\mu \mathrm{m}$ purpose nylon mesh. Cell suspensions were poured in 2 burettes. Mouse anti-rat CD29, CD44, and CD45 monoclonal antibodies and isotype controls were added via flow cytometry in order to identify the MSC phenotype (Jia et al., 2009; Zhao and Cai, 2010).

After anaesthetizing rats with chloral hydrate, the abdominal cavity was opened under sterile conditions and the pancreas was removed. After removing the surrounding tissues of the pancreas, the pancreatic parenchyma was injected with Grey's balanced salt solution, 
containing $0.02 \%$ chain enzyme protease E, $0.05 \%$ collagenase, and $0.19 \%$ DNA enzyme. The pancreas was cut into pieces and added into $50-\mathrm{mL}$ enzyme digestive juice, which was then oscillated in water at $37^{\circ} \mathrm{C}$ for $20 \mathrm{~min}$. After the enzyme digestive juice was filtered with a $74-\mu \mathrm{m}$ steel and centrifuged at $700 \mathrm{~g}$ for $5 \mathrm{~min}$, the filtrate was collected. The precipitate was centrifuged, washed twice with Hank's solution at $4^{\circ} \mathrm{C}$, and then re-suspended in $10 \mathrm{~mL}$ Hank's solution. Subsequently, $18 \%$ Nycodenz was added to the suspension of mixed cells in a 1:2 volume. Five milliliters $18 \%$ Nycodenz, $5 \mathrm{~mL}$ cell suspension with Nycodenz, and 2 $\mathrm{mL}$ Dulbecco's modified Eagle's medium (DMEM) were added to a $15-\mathrm{mL}$ centrifuge tube. After centrifugation at $1400 \mathrm{~g}$ for $5 \mathrm{~min}$, a layer of white interface was found between the Nycodenz solution and the medium layer. This layer was confirmed to be PSCs. The PSCs were collected, re-suspended in high-glucose DMEM containing $20 \%$ fetal bovine serum, hydroxyethyl piperazineethanesulfonic acid, penicillin, and streptomycin, and were then incubated at $37^{\circ} \mathrm{C}$ in a $5 \% \mathrm{CO}_{2}$ atmosphere. The medium was changed after $24 \mathrm{~h}$ and then every $48 \mathrm{~h}$ thereafter. When $80 \%$ confluence was achieved, the cells were passaged (Apte et al., 1998; Bachem et al., 1998).

\section{Preparation of $\mathrm{I} \kappa \mathrm{B} \alpha \mathrm{M}-\mathrm{MSCs}$}

After constructing an adeno-associated virus vector carrying the IкB $\alpha \mathrm{M}$ gene and infected AAV2-293 cells, the expression of the IкB $\alpha$ M gene was detected. rAAV2 particles were collected as described previously (Zhang et al., 2012). MSCs were transfected with IкBaM as described previously (Shelling and Smith, 1994; Pieroni et al., 1998). When MSCs reached 60 to $80 \%$ confluence, the medium was replaced with serum-free medium. Each hole was filled with $100 \mu \mathrm{L}$ rAAV2-EGFP, which induced multiple infections reaching $10^{6}$ cells/L. The medium was mixed gently and then incubated at $37^{\circ} \mathrm{C}$ in a $5 \% \mathrm{CO}_{2}$ atmosphere. After 6 to 12 $\mathrm{h}$, the medium was replaced with complete medium containing serum, and the MSCs were cultured again.

\section{I $\kappa \mathrm{B} \alpha \mathrm{M}-\mathrm{MSCs}$ injected into the CP model rats in vivo}

After 60 days, the intercellular adhesion molecule-1 (ICAM-1), connective tissue growth factor (CTGF), IL-1, IL-6, IL-8, TNF- $\alpha$, tissue inhibitor of metalloproteinase (TIMP)1, TIMP-2, FN, IL-10, matrix metalloproteinase (MMP)-1, MMP-2, MMP-3, and MMP-9 levels in the rat pancreas of each group (A, B, C1, C2, C3, D) were detected.

\section{Immunocytochemistry}

Immunocytochemistry was carried out as described previously (Choi et al., 2009) using an Olympus BX51 microscope (Olympus, Tokyo, Japan). Images were digitized and then processed using the Photoshop CS5.0 software (Adobe Systems, Mountain View, CA, USA).

\section{3-(4,5-Dimethylthiazol-2-yl)-2,5-diphenyltetrazolium bromide (MTT) assay}

Rat PSCs were isolated and cultured. After trypsinization, 100,000 cells/well were seeded on 6-well plates. After reaching subconfluence, the cells were serum-starved and stim- 
ulated with no addition, $2 \mathrm{ng} / \mathrm{mL}$ TGF, $1 \mathrm{ng}$ cholecystokinin, or $1 \mu \mathrm{g}$ gastrin for $24 \mathrm{~h}$. The stimulating factors were replaced after $12 \mathrm{~h}$. After adding $100 \mu \mathrm{g} / \mathrm{mL}$ MTT (Sigma, USA), the cells were incubated for $2 \mathrm{~h}$. The supernatant was removed, and $250 \mu \mathrm{L} /$ well dimethyl sulfoxide (Sigma, USA) was added. The reaction products were transferred to microtiter plates and read in a standard microplate reader at $570 \mathrm{~nm}$.

\section{Enzyme-linked immunosorbent assay (ELISA)}

Rat pancreatic tissues were rinsed with cold saline and dried with filter paper. The pancreatic tissue was ground using a stamp mill at 10,000-15,000 rpm to make a $10 \%$ homogenate. The prepared 10\% homogenate was centrifuged at $3000 \mathrm{rpm}$ for $10-15 \mathrm{~min}$ at a low temperature. Supernatant $(100 \mu \mathrm{L})$ was extracted to determine cytokine content. After collection, the blood was allowed to stand for 1-2 $\mathrm{h}$, placed in a centrifuge tube, and then centrifuged at $3000 \mathrm{rpm}$ for $15 \mathrm{~min}$. ELISA was performed in accordance with manufacturer instructions, provided by Shanghai Resun Biological Technology Co. Ltd.

\section{Indirect co-culture of bone marrow MSCs and PSCs}

Indirect co-culture was carried out as described previously (Zhang et al., 2012). PSCs were added to the lower layer of Transwell plates pre-cultured with fifth-generation MSCs, rAAV2-MSCs, and IкB $\alpha M-M S C s$. The Transwell culture plates were placed in a heated incubator for indirect co-culture at $37^{\circ} \mathrm{C}$ in a $5 \% \mathrm{CO}_{2}$ atmosphere. The assembly of the Transwell non-contact co-culture system was completed following methods described (Parekkadan et al., 2011). Cell growth was observed at regular intervals.

\section{GeneChip Rat Genome 2302.0 array}

GeneChip (Affymetrix) was used to extract the RNA of IкB $\alpha$ M-MSCs and PSCs. The Qiagen MidiKit was used to separate and purify mRNA. After adding reverse transcriptase, biotin-labeled cDNA probes were purified. The biotin-labeled cDNA probe was detected following the method described (Ohnishi et al., 2007) using the GeneChip Rat Genome 2302.0 array (Affymetrix) with gene chips containing 31,099 genes (Cambon et al., 2007; Alberts et al., 2007).

\section{Statistical analysis}

Differences among groups were analyzed using one-way analysis of variance. Data are reported as means \pm standard deviation and were analyzed with the SPSS 17.0 statistical software. In a two-tailed test, $\mathrm{P}<0.05$ was considered to indicate statistical significance.

\section{RESULTS}

\section{Bone marrow MSCs, PSCs, and $\mathrm{I} \kappa \mathrm{B} \alpha \mathrm{M}-\mathrm{MSCs}$}

After 3 generations, the morphology of the MSCs was homogeneously fibrous (Figure 1). 


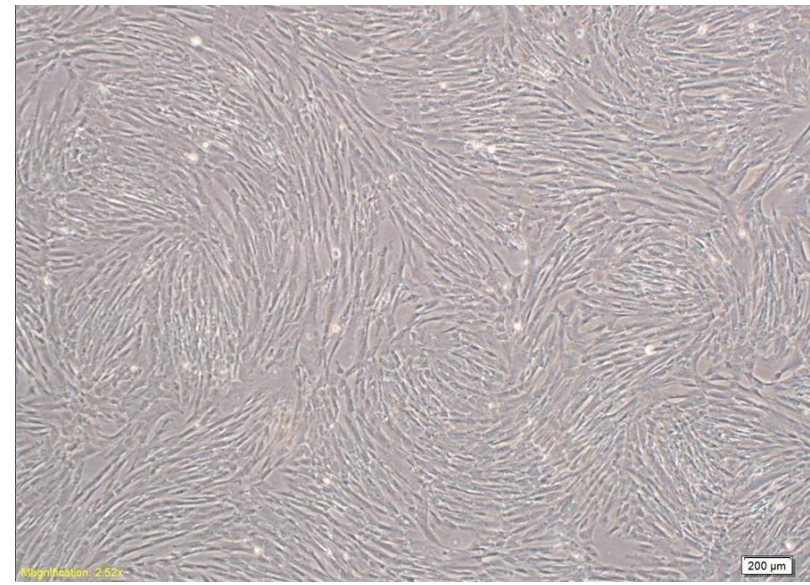

Figure 1. After 3 generations, the morphology of MSCs were homogeneously fibrous.

After $72 \mathrm{~h}$, the PSCs were enlarged and had well-developed pseudopodia, showing stellate- or squid-like shapes. After stimulation by $328-\mathrm{nm}$ ultraviolet light, freshly isolated cells emitted blue-green autofluorescence. $\alpha$-SMA (positive staining) was observed in the cytoplasm of PSCs, which were distributed in a fibrous manner (Figure 2). We constructed a recombinant vector, pcDNA3.0-I $\mathrm{KB} \alpha \mathrm{M}$, to transfect and package the adeno-associated virus. We used T7 BGH rev universal primers to sequence the adeno-associated virus in 2 directions (Figure 3). The transfected IкBaM-MSCs were able to emit green fluorescence under a fluorescence microscope (Figure 4).

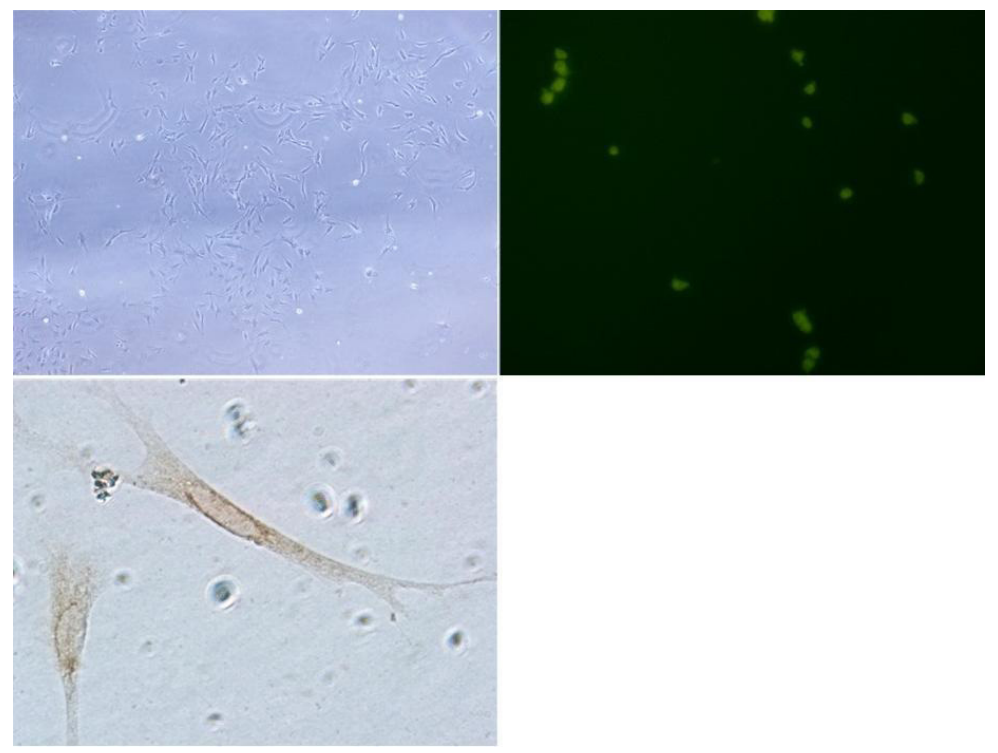

Figure 2. After 72 h, PSCs showed large and well-developed stellate-shaped or "squid-like" pseudopodia. Freshly isolated cells emitted blue-green autofluorescence after stimulation with $328 \mathrm{~nm}$ UV. $\alpha$-SMA (positive staining) was observed in the cytoplasm of PSCs, showing a fibrous distribution. 

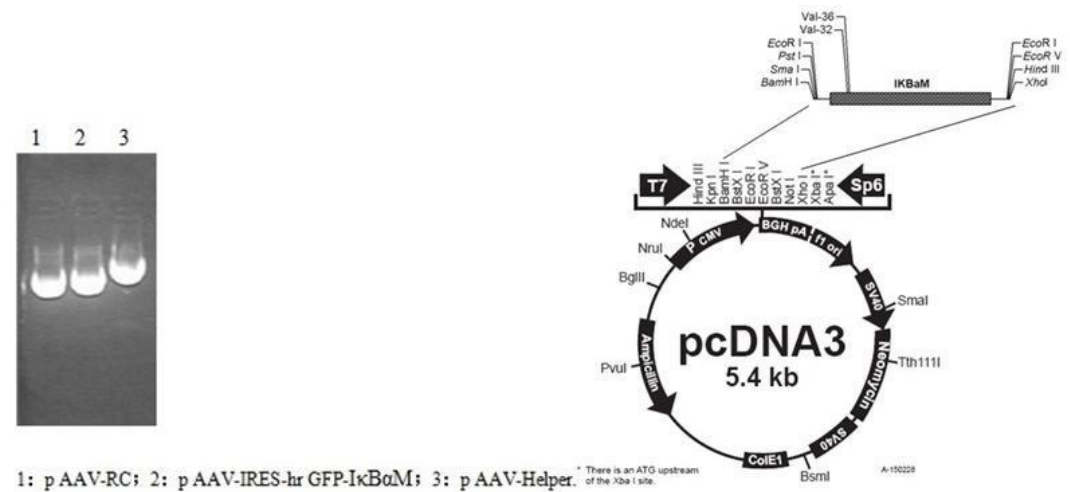

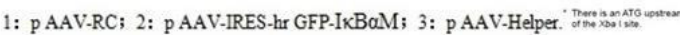

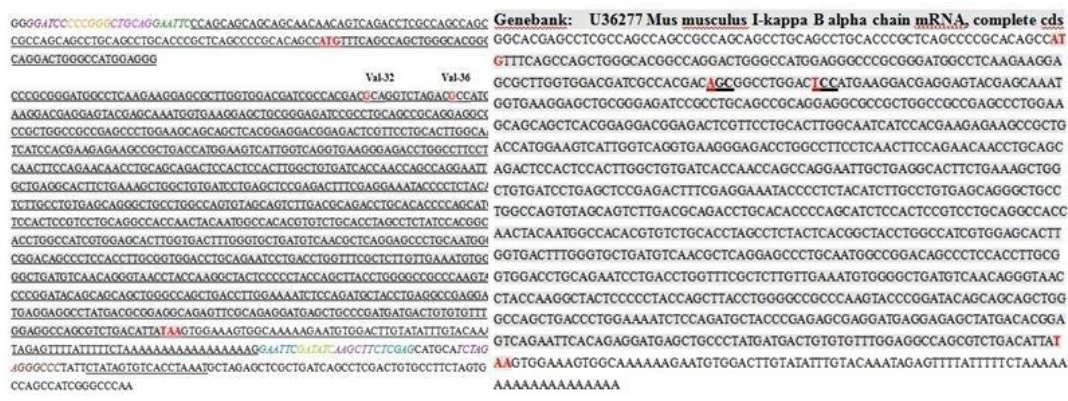

Figure 3. Results of bi-directional sequence determination of the adeno-associated virus. The T7 BGH rev universal primers were used for sequence confirmation.
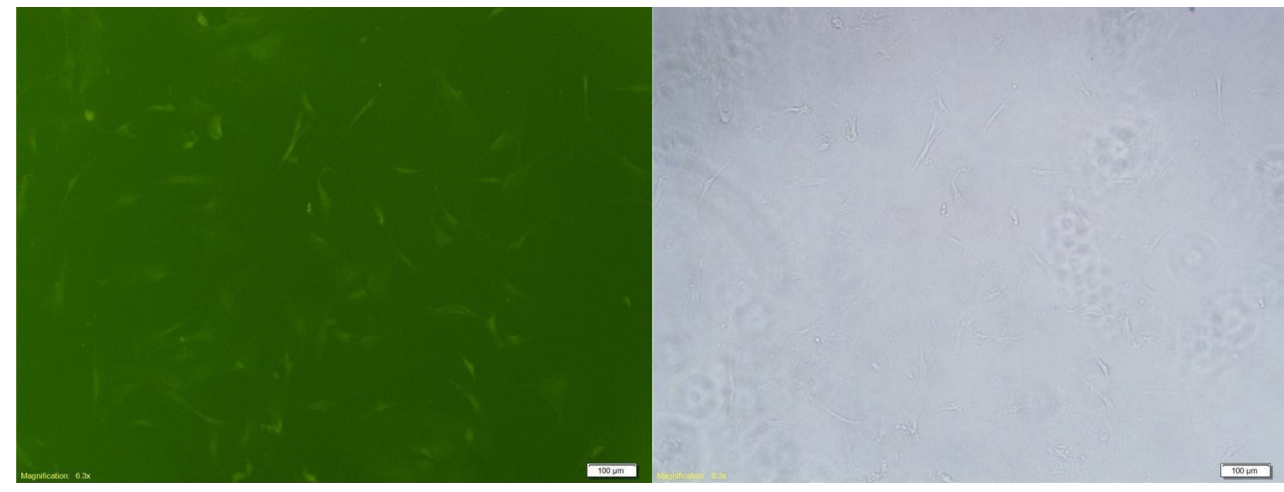

Figure 4. Transfected IкB $\alpha \mathrm{M}-\mathrm{MSC}$ s were observed to emit green fluorescence under a fluorescence microscope.

\section{Fibrosis image of each group}

The extent of fibrosis in Groups B, C, and D were less pronounced than that of Group A. The fibrosis in Groups C1, C2, and C3 were less pronounced than that of Groups B and D (Figure 5). 


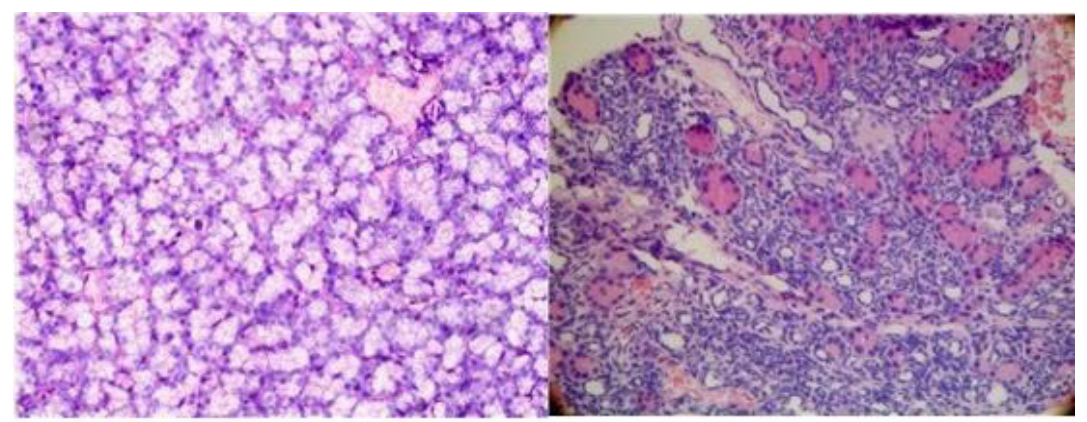

Group A

Group B

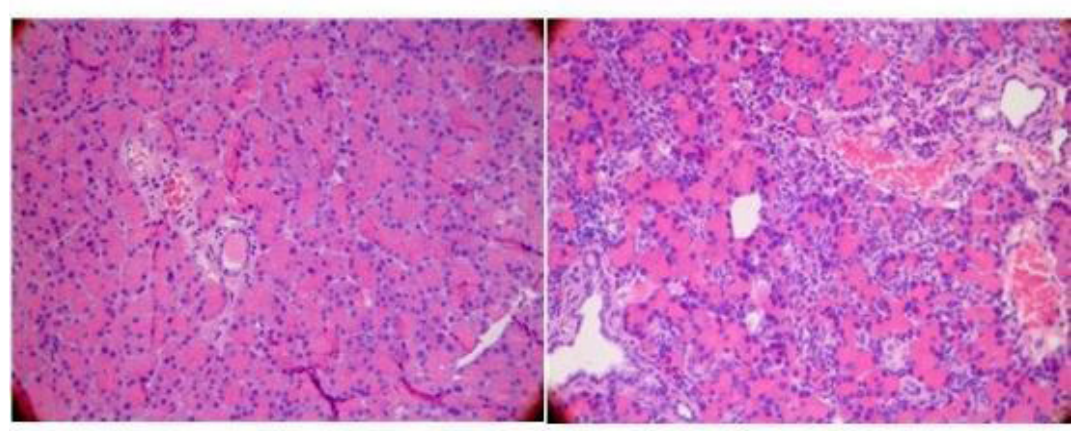

Group Cl

Group C2

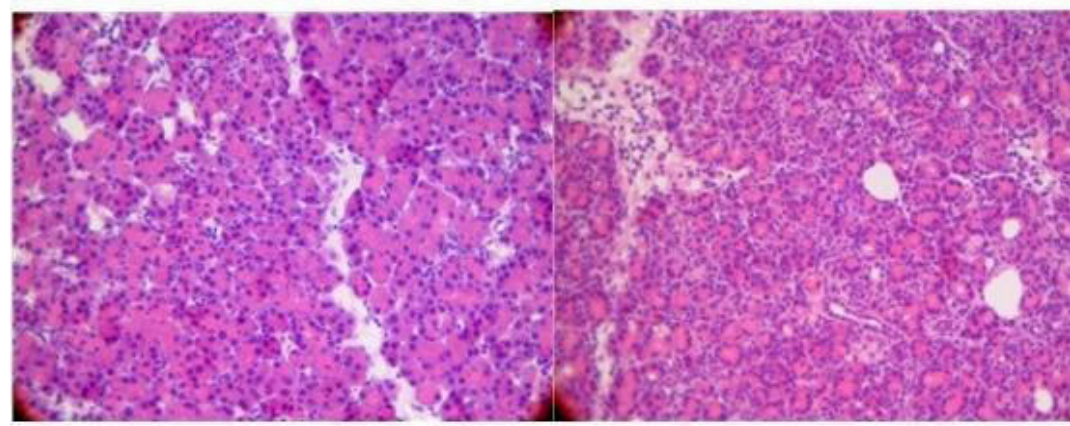

Group C3

Group D

Figure 5. Fibrosis of Group B, Group C, and Group D were lower than that in Group A.

\section{Immunohistochemical staining}

The NF- $\kappa \mathrm{B}$ levels in Groups B, C, and D were lower than those of Group A. The NF$\kappa \mathrm{B}$ levels in Groups $\mathrm{C} 1, \mathrm{C} 2$, and $\mathrm{C} 3$ were lower than those of Groups B and D (Figure 6). Glial fibrillary acidic protein and terminal transferase dUTP end-labeling double staining suggested PSC apoptosis in the pancreas (Figure 7). 

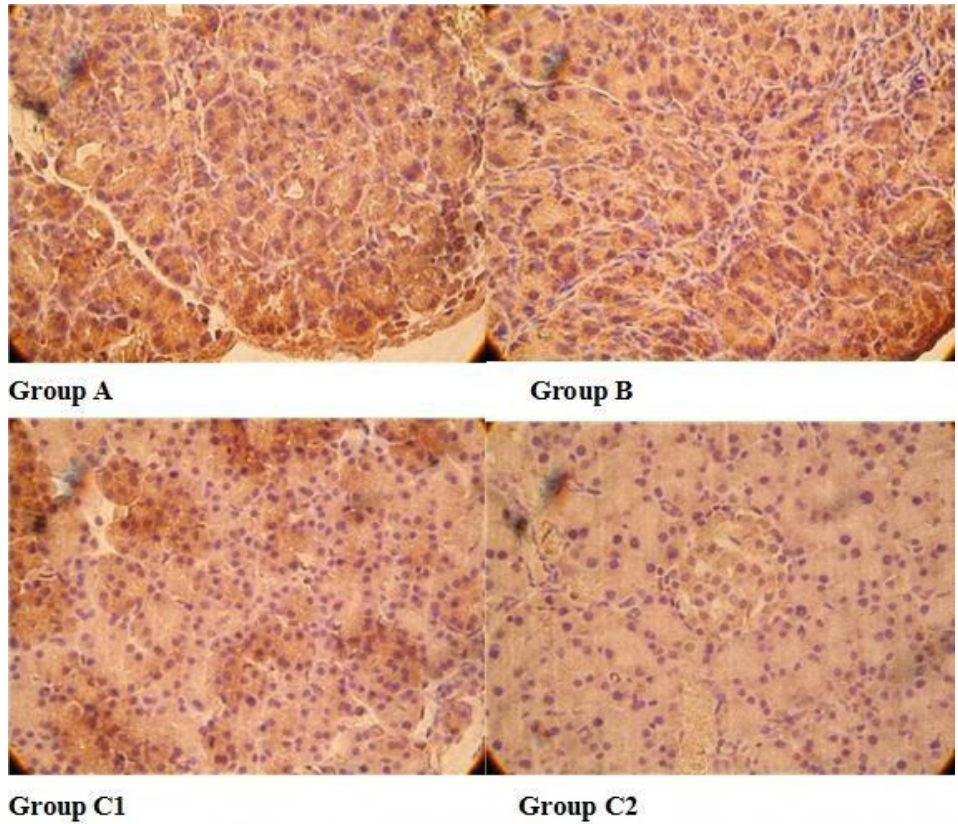

Group C2

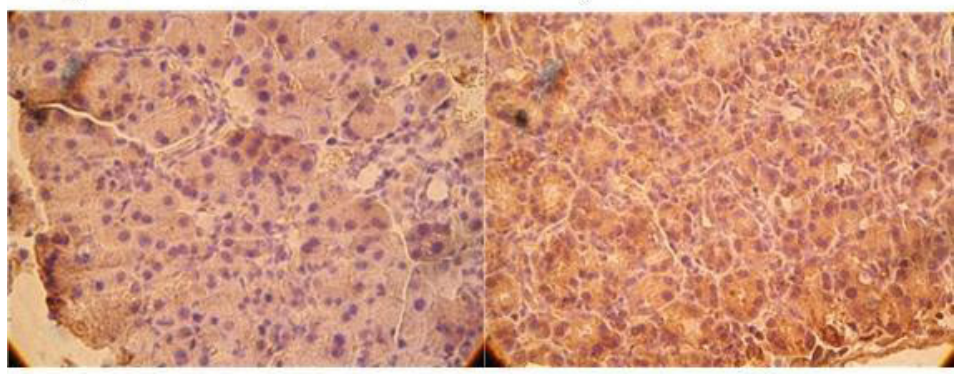

Group C3

Group D

Figure 6. NF-кB in Group B, Group C, and Group D were reduced compared to that of Group A.

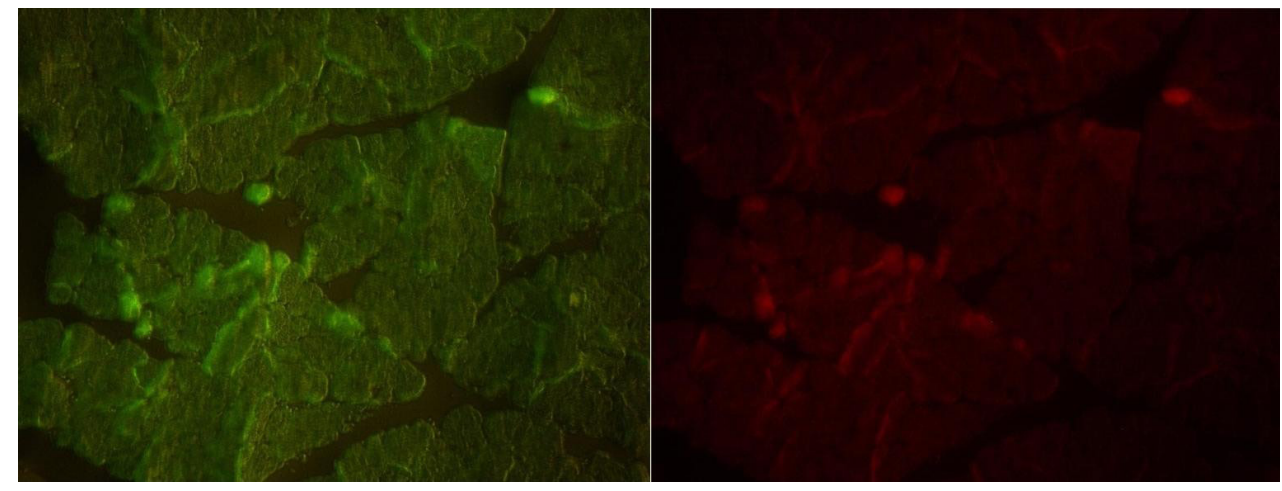

Figure 7. GFAP and TUNEL-double staining indicated apoptosis of PSC in the pancreas. 


\section{ELISA}

The expression levels of IL-1, IL-6, IL-8, FN, TIMP-1, TIMP-2, TNF- $\alpha$, CTGF, ICAM- 1 , and TGF- $\beta_{1}$ were lower in Group $C$ than in Groups A, B, and D $(\mathrm{P}<0.05)$. The expression levels of MMP-1, MMP-2, MMP-3, MMP-9, and IL-10 were higher in Group C than in Groups B and D $(\mathrm{P}<0.05)$. No statistically significant difference was observed in expression levels between Groups B and D $(\mathrm{P}>0.05)$. The expression levels of IL-1, IL-6, IL-8, FN, TIMP-1, TIMP-2, TNF- $\alpha$, CTGF, P65, ICAM- 1 , and TGF- $\beta_{1}$ were lower in Groups B, C, and $\mathrm{D}$ than in Group A $(\mathrm{P}<0.05)$. The expression levels of MMP-1, MMP-2, MMP-3, MMP-9, and IL-10 were higher in Groups B, C, and D than in Group A $(\mathrm{P}<0.05)$.

Expression levels of IL-1, IL-6, IL-8, FN, TIMP-1, TIMP-2, TNF- $\alpha$, CTGF, ICAM1 , TGF- $\beta_{1}$, P65, MMP-1, MMP-2, MMP-3, MMP-9, and IL-10 in rat serum are presented in Tables 1 and 2 .

After the indirect co-culture of IкB $\alpha \mathrm{M}-\mathrm{MSCs} / \mathrm{PSCs}$ and MSCs/PSCs, changes in the gene sequences of PSCs were observed in both groups. After further analysis and processing to filter biologically significant genes, some changes in signaling pathway genetic sequences were observed, including PPAR, Toll-like receptor, VEGF, hedgehog, JAK-STAT, MAPK, mTOR, TGF- $\beta$, NOD-like receptor, NOTCH, ERBB, chemokine, WNT, TGF- $\beta_{1}$ smad-2/3, and P53.

\section{DISCUSSION}

$\mathrm{I} \kappa \mathrm{B} \alpha$ is an inhibitor of NF- $\kappa \mathrm{B}$ that is commonly found in various cell types (Kim et al., 2012). The ankyrin repeat region of IkB $\alpha$ proteins combines with the Rel homology do-

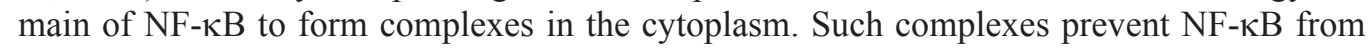
entering the nucleus to activate transcription and maintain it in a non-active state in the cytoplasm. TNF- $\alpha$ and IL-1 transduce signals to NIK by binding with a receptor. They then

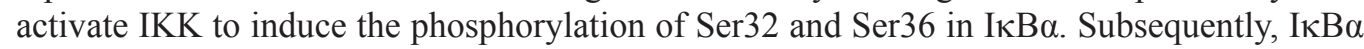
is ubiquitin oriented and thus is degraded. I $\mathrm{B} \alpha$ degradation induces dissociation of the NF$\kappa \mathrm{B}-\mathrm{I} \kappa \mathrm{B} \alpha$ complex. Finally, free NF- $\kappa \mathrm{B}$ dimers migrate to the nucleus to induce the expression of related genes.

The NF- $\kappa \mathrm{B}$ signaling pathway plays an important role in CP development. We con-

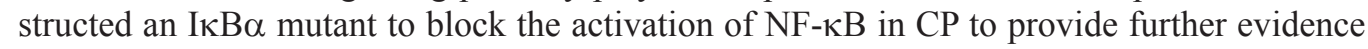

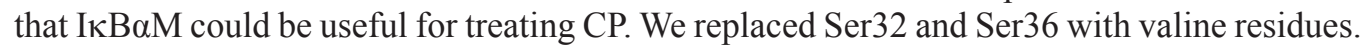
I $\kappa \mathrm{B} \alpha \mathrm{M}$ retained its binding activity to I $\kappa \mathrm{B}$ without inducing phosphorylation and degradation. Subsequently, NF- $\mathrm{kB}$ could not be activated. Several studies have reported that MSCs are useful in repairing damaged organization and in promoting rebirth. This study was therefore

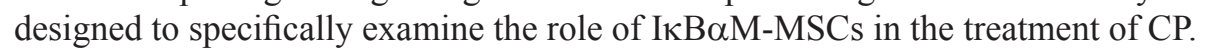

Several studies have indicated that blocking the NF-кB signaling pathway and injecting MSCs can regulate inflammatory factors and apoptosis of PSCs in acute pancreatitis. The results of the present study suggest that these events can also occur in CP. In this study, we found that inflammation in the pancreas of the I $\mathrm{B} \alpha \mathrm{M}$ transfection group was significantly reduced compared to that of the pancreatitis group. This result suggests that I $\mathrm{B} \alpha \mathrm{M}$ inhibited the inflammatory response in the early period of $\mathrm{CP}$ and played a protective role in the occurrence and development of $\mathrm{CP}$. 


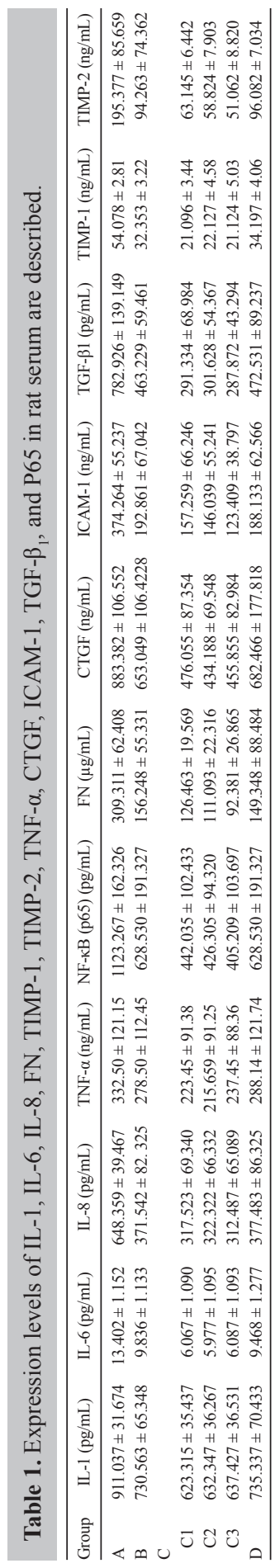


Table 2. Expression levels of MMP-1, MMP-2, MMP-3, MMP-9, and IL-10 in rat serum are described.

\begin{tabular}{lccccc}
\hline Group & IL-10 $(\mathrm{pg} / \mathrm{mL})$ & MMP-1 $(\mathrm{ng} / \mathrm{mL})$ & MMP-2 $(\mathrm{ng} / \mathrm{mL})$ & MMP-3 $(\mathrm{ng} / \mathrm{mL})$ & MMP-9 $(\mathrm{ng} / \mathrm{mL})$ \\
\hline A & $314.325 \pm 31.067$ & $309.411 \pm 18.479$ & $286.346 \pm 22.764$ & $412.236 \pm 55.294$ & $264.339 \pm 36.195$ \\
B & $590.094 \pm 55.237$ & $388.934 \pm 50.363$ & $367.422 \pm 17.992$ & $645.331 \pm 150.424$ & $326.526 \pm 70.465$ \\
C & & & & & \\
C1 & $683.289 \pm 90.276$ & $732.227 \pm 23.561$ & $420.351 \pm 30.438$ & $1102.394 \pm 70.665$ & $904.589 \pm 27.359$ \\
C2 & $674.035 \pm 88.274$ & $741.465 \pm 14.326$ & $395.834 \pm 19.665$ & $1034.287 \pm 76.009$ & $887.638 \pm 39.442$ \\
C3 & $680.799 \pm 91.624$ & $759.306 \pm 12.744$ & $411.371 \pm 15.279$ & $1206.267 \pm 102.381$ & $979.355 \pm 55.367$ \\
D & $586.471 \pm 60.372$ & $391.894 \pm 38.452$ & $394.117 \pm 25.864$ & $676.953 \pm 172.135$ & $314.885 \pm 83.204$ \\
\hline
\end{tabular}

Pancreatic fibrosis is mainly caused by the imbalance between the synthesis and deposition of the ECM in the pancreatic tissue. Type I collagen, type III collagen, and FN are all integral components of the ECM in the pancreatic tissue (Akita et al., 2012; Yan et al., 2012). Reduction of these 3 factors can prevent deposition of the ECM in the pancreatic tissue and

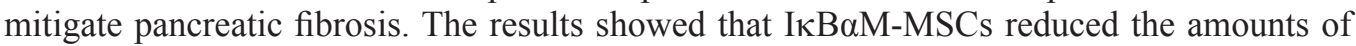
type I collagen, type III collagen, and FN in rats. The pathological specimens also suggested a significant difference in pancreatic fibrosis among groups. The pancreatic fibrosis in Groups $\mathrm{C} 1, \mathrm{C} 2$, and $\mathrm{C} 3$ was less pronounced than that in Groups A, B, and D.

MMPs, such as MMP-1, MMP-2, MMP-3, and MMP-9, can promote degradation of the ECM in the pancreas while inhibiting expressions of TIMP-1 and TIMP-2 (Prakash et

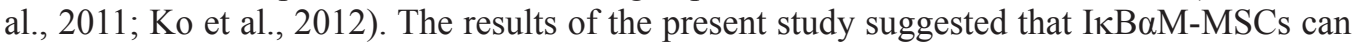
increase expression levels of MMP-1, MMP-2, MMP-3, and MMP-9 in the pancreatic fibrosis tissue and reduce those of TIMP-1 and TIMP-2. Pancreatic fibrosis was also improved in some pancreatic tissues of Groups $\mathrm{C} 1, \mathrm{C} 2$, and $\mathrm{C} 3$.

In this study, the expression levels of IL-10 and TGF- $\beta_{1}$ increased significantly in Groups $\mathrm{C} 1, \mathrm{C} 2$, and $\mathrm{C} 3$ relative to Groups B and D. Therefore, blocking the NF- $\mathrm{KB}$ signaling pathway can increase expression levels of IL-10 and TGF- $\beta$. Several studies have suggested that as a secreted protein, CCN, the CTGF can stimulate cell mitosis, chemotaxis, proliferation, and ECM formation (Grotendorst et al., 2000). Abreu et al. (2002) found a synergistic relationship between CTGF and TGF- $\beta_{1}$. IL-10 is an effective antifibrotic cytokine. Endogenous IL-10 may limit pancreatic gland atrophy and fibrosis as well as reduce the expression level of TGF- $\beta_{1}$ in pancreatic acinar cells and interstitial cells (Bendicho et al., 2005; Apte et al., 2007).

Several studies (Rakonczay Jr. et al., 2008) have shown that over-activation of NF- $\kappa B$ in the early course of $\mathrm{CP}$ can increase expression levels of many pro-inflammatory cytokines, inflammatory mediators, adhesion molecules, and acute phase proteins, all of which can promote inflammation, activate PSCs, and accelerate pancreatic fibrosis in CP. Therefore, inhibition of inappropriate activation of NF- $\mathrm{KB}$ in the early stage of $\mathrm{CP}$ could reduce the overproduction of inflammatory mediators and cytokines. Thus, the initial stage of CP can be inhibited to a certain extent in order to delay its further development.

TGF- $\beta_{1}$ is a multifunctional cytokine that combines with its receptors, RI and RII, at the cell surface to form complexes and regulate cell growth and differentiation (Wang et al., 2012). TGF- $\beta_{1}$ complexes play important roles in tissue fibrosis and repair by stimulating cell matrix synthesis and inhibiting degradation. TGF- $\beta_{1}$ can activate PSC to induce fibroblast differentiation and secretion of various components of the ECM, such as type I collagen and FN. Several studies have revealed that PSCs can induce TGF- $\beta_{1}$ synthesis. Therefore, PSCs

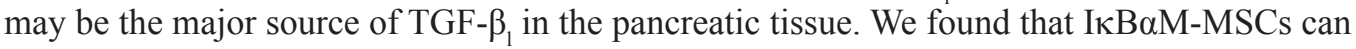


reduce the expression level of TGF- $\beta_{1}$. Through gene sequence detection, we found that the TGF- $\beta_{1}$, Smad2/3, CycA, and ORC genes of PSC sequences were differentially expressed after

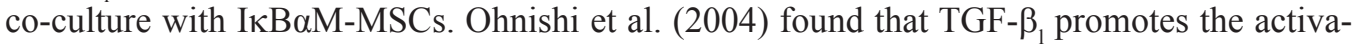
tion of PSCs through the Smad2-dependent pathway and that PSCs infected by the adenovirus with the Smad2-dominant-negative gene inhibit PSC activation. I $\kappa \mathrm{B} \alpha \mathrm{M}-\mathrm{MSCs}$ can reduce the secretion of TGF- $\beta_{1}$, thereby inhibiting the transduction of the TGF- $\beta$-smad- $2 / 3$ signaling pathway. This process can affect DNA biosynthesis and inhibit the proliferation of PSCs, which benefit the treatment of CP.

In our previous study (Liu and Qin, 2011), we confirmed that PSCs play key roles in $\mathrm{CP}$; however, the influencing factors are complex and difficult to clearly analyze in vivo. To

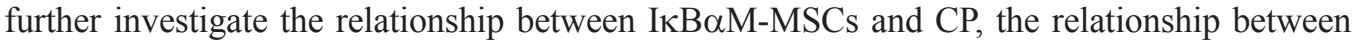
I $\mathrm{B} \alpha \mathrm{M}-\mathrm{MSCs}$ and PSCs should be investigated. A Transwell culture plate is an indirect culture system that can be used to observe the effect of IкBaM-MSCs on PSCs. Further studies using ELISA and the GeneChip Rat Genome 2302.0 array are currently underway to determine the mechanism linking IкBaM-MSCs and PSCs. The in vitro test of the present study revealed the possible signaling pathway regulating the inflammatory factors and apoptosis of PSCs.

Extracellular signal-regulated protein kinase, p38, and c-Jun N-terminal protein kinase are 3 important members of the MAPK superfamily. MAPK plays an important role in PSC activation (McCarroll et al., 2003). The MAPK signaling pathway was downregulated in $\mathrm{I} \kappa \mathrm{B} \alpha \mathrm{M}-\mathrm{MSC}$ /PSCs, especially $\mathrm{p} 38$.

The encoded product of the p53 gene is composed of 393 amino acids divided into WTP53 and MTP53. WTP53 promotes apoptosis, reduces the expression level of the endogenous bcl-2 protein, and inhibits its function by downregulating the bcl-2 gene. WTP53 increases the target gene bax to improve the expression of the intracellular bax protein, which induces an imbalance in the bcl-2/bax protein and promotes apoptosis. Pei et al. (2008) found that NF- $\mathrm{KB}$ may inhibit cell apoptosis by upregulating the expression of the bcl-2 gene. In this study, Reprimo, Gadd45, and Cyclin B gene fragments were expressed through the p53 signaling pathway. Therefore, I $\mathrm{B} \alpha \mathrm{M}$ may arrest the cell cycle through the Reprimo/Gadd45-Cyclin $\mathrm{B}$ signaling pathway. Moreover, PERP, CytC, and IGF gene fragments showed genetic variations. Combined with previous studies, we can speculate that I $\mathrm{B} \alpha \mathrm{M}$ induces PSC apoptosis through the P53-IGF and P53-PERP-CytC-CASP9-CASP3 signaling pathways.

Our previous study (Zhang et al., 2009) showed that the self-activation of PSCs can be limited and apoptosis of PSCs can be induced by inhibiting the activation of NF- $\kappa B$ in PSCs. Therefore, I $\mathrm{B} \alpha \mathrm{M}$ inhibits the factors influencing $\mathrm{CP}$ and reduces pancreatic fibrosis. Com-

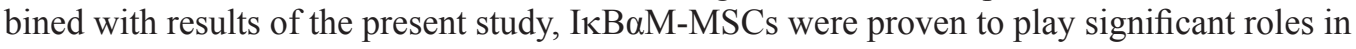
controlling inflammatory factors and pancreatic fibrosis of CP.

\section{ACKNOWLEDGMENTS}

Research supported by the National Natural Science Foundation of China (\#30972928).

\section{REFERENCES}

Abreu JG, Ketpura NI, Reversade B and De Robertis EM (2002). Connective-tissue growth factor (CTGF) modulates cell signalling by BMP and TGF-beta. Nat. Cell Biol. 4: 599-604.

Akita S, Kubota K, Kobayashi A, Misawa R, et al. (2012). Role of bone marrow cells in the development of pancreatic 
fibrosis in a rat model of pancreatitis induced by a choline-deficient/ethionine-supplemented diet. Biochem. Biophys. Res. Commun. 420: 743-749.

Alberts R, Terpstra P, Hardonk M, Bystrykh LV, et al. (2007). A verification protocol for the probe sequences of Affymetrix genome arrays reveals high probe accuracy for studies in mouse, human and rat. BMC Bioinformatics 8: 132.

Aoki H, Ohnishi H, Hama K, Ishijima T, et al. (2006). Autocrine loop between TGF-beta1 and IL-1beta through Smad3and ERK-dependent pathways in rat pancreatic stellate cells. Am. J. Physiol. Cell Physiol. 290: C1100-C1108.

Apte MV, Haber PS, Applegate TL, Norton ID, et al. (1998). Periacinar stellate shaped cells in rat pancreas: identification, isolation, and culture. Gut 43: 128-133.

Apte MV, Haber PS, Darby SJ, Rodgers SC, et al. (1999). Pancreatic stellate cells are activated by proinflammatory cytokines: implications for pancreatic fibrogenesis. Gut 44: 534-541.

Apte M, McCarroll J, Pirola R and Wilson J (2007). Pancreatic MAP kinase pathways and acetaldehyde. Novartis Found. Symp. 285: 200-211.

Bachem MG, Schneider E, Gross H, Weidenbach H, et al. (1998). Identification, culture, and characterization of pancreatic stellate cells in rats and humans. Gastroenterology 115: 421-432.

Bendicho MT, Guedes JC, Silva NN, Santana GO, et al. (2005). Polymorphism of cytokine genes (TGF-beta1, IFNgamma, IL-6, IL-10, and TNF-alpha) in patients with chronic pancreatitis. Pancreas 30: 333-336.

Cambon AC, Khalyfa A, Cooper NG and Thompson CM (2007). Analysis of probe level patterns in Affymetrix microarray data. BMC Bioinformatics 8: 146.

Choi EK, Kim MH, Jang SJ, Lee KH, et al. (2009). Differences in pancreatic immunohistochemical staining profiles of TGF-beta1, MMP-2, and TIMP-2 between autoimmune and alcoholic chronic pancreatitis. Pancreas 38: 739-745.

Ellenrieder V, Schneiderhan W, Bachem M and Adler G (2004). Fibrogenesis in the pancreas. Rocz. Akad. Med. Bialymst. 49: 40-46.

Ghosh S, May MJ and Kopp EB (1998). NF-kappa B and Rel proteins: evolutionarily conserved mediators of immune responses. Annu. Rev. Immunol. 16: 225-260.

Grotendorst GR, Lau LF and Perbal B (2000). CCN proteins are distinct from and should not be considered members of the insulin-like growth factor-binding protein superfamily. Endocrinology 141: 2254-2256.

Haber PS, Keogh GW, Apte MV, Moran CS, et al. (1999). Activation of pancreatic stellate cells in human and experimental pancreatic fibrosis. Am. J. Pathol. 155: 1087-1095.

Habisch H, Zhou SX, Siech M and Bachem MG (2010). Interaction of stellate cells with pancreatic carcinoma cells. Cancers 2: 1661-1682.

Jia GQ, Zhang MM, Yang P, Cheng JQ, et al. (2009). Effects of the different culture and isolation methods on the growth, proliferation and biology characteristics of rat bone marrow mesenchymal stem cells. Sichuan. Da Xue Xue Bao Yi. Xue Ban. 40: 719-723.

Kim JY, Park HJ, Um SH, Sohn EH, et al. (2012). Sulforaphane suppresses vascular adhesion molecule-1 expression in TNF-alpha-stimulated mouse vascular smooth muscle cells: involvement of the MAPK, NF-kappaB and AP-1 signaling pathways. Vascul. Pharmacol. 56: 131-141.

Ko HS, Lee HJ, Kim SH and Lee EO (2012). Piceatannol suppresses breast cancer cell invasion through the inhibition of MMP-9: involvement of PI3K/AKT and NF-kappaB pathways. J. Agric. Food Chem. 60: 4083-4089.

Liu CJ and Qin T (2011). Effects of bone marrow mesenchymal stem cells on pancreatic stellate cells of rats with chronic pancreatitis. Chin. J. Exp. Surg. 28: 1279-1281.

McCarroll JA, Phillips PA, Park S, Doherty E, et al. (2003). Pancreatic stellate cell activation by ethanol and acetaldehyde: is it mediated by the mitogen-activated protein kinase signaling pathway? Pancreas 27: 150-160.

Ohnishi H, Miyata T, Yasuda H, Satoh Y, et al. (2004). Distinct roles of Smad2-, Smad3-, and ERK-dependent pathways in transforming growth factor-beta1 regulation of pancreatic stellate cellular functions. J. Biol. Chem. 279: 8873-8878.

Ohnishi S, Sumiyoshi H, Kitamura S and Nagaya N (2007). Mesenchymal stem cells attenuate cardiac fibroblast proliferation and collagen synthesis through paracrine actions. FEBS Lett. 581: 3961-3966.

Omary MB, Lugea A, Lowe AW and Pandol SJ (2007). The pancreatic stellate cell: a star on the rise in pancreatic diseases. J. Clin. Invest. 117: 50-59.

Parekkadan B, Upadhyay R, Dunham J, Iwamoto Y, et al. (2011). Bone marrow stromal cell transplants prevent experimental enterocolitis and require host CD11b+ splenocytes. Gastroenterology 140: 966-975.

Pei HH, Qiao WH, Bai L, Miao F, et al. (2008). Effect of peroxisome proliferators-activated receptor-gamma (PPAR gamma) on expression of NF-kB in experimental pancreatitis. Zhongguo Wei Zhong. Bing. Ji. Jiu. Yi. Xue 20: 297-298.

Phillips P (2012). Pancreatic Stellate Cells and Fibrosis. In: Pancreatic Cancer and Tumor Microenvironment (Grippo PJ and Munshi HG, eds.). Transworld Research Network, Trivandrum, 29-53.

Phillips PA, McCarroll JA, Park S, Wu MJ, et al. (2003). Rat pancreatic stellate cells secrete matrix metalloproteinases: implications for extracellular matrix turnover. Gut 52: 275-282. 
Pieroni L, Fipaldini C, Monciotti A, Cimini D, et al. (1998). Targeted integration of adeno-associated virus-derived plasmids in transfected human cells. Virology 249: 249-259.

Prakash M, Kale S, Ghosh I, Kundu GC, et al. (2011). Hyaluronan-binding protein 1 (HABP1/p32/gC1qR) induces melanoma cell migration and tumor growth by NF-kappa B dependent MMP-2 activation through integrin alpha(v) $\beta(3)$ interaction. Cell Signal. 23: 1563-1577.

Rakonczay Z Jr, Hegyi P, Takacs T, McCarroll J, et al. (2008). The role of NF-kappaB activation in the pathogenesis of acute pancreatitis. Gut 57: 259-267.

Shelling AN and Smith MG (1994). Targeted integration of transfected and infected adeno-associated virus vectors containing the neomycin resistance gene. Gene Ther. 1: 165-169.

The Ministry of Science and Technology of People's Republic of China (2006). Guidance to Treat Experimental Animals.

Wang MK, Sun HQ, Xiang YC, Jiang F, et al. (2012). Different roles of TGF-beta in the multi-lineage differentiation of stem cells. World J. Stem Cells 4: 28-34.

Yan MX, Ren HB, Kou Y, Meng M, et al. (2012). Involvement of nuclear factor kappa B in high-fat diet-related pancreatic fibrosis in rats. Gut Liver 6: 381-387.

Zhang B, Yang S, Zhang Y, Sun Z, et al. (2012). Co-culture of mesenchymal stem cells with umbilical vein endothelial cells under hypoxic condition. J. Huazhong Univ. Sci. Technol. Med. Sci. 32: 173-180.

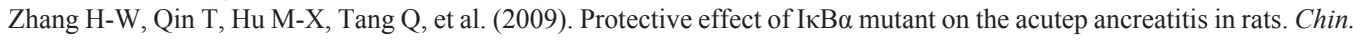
J. Exp. Surg. 26: 61-63.

Zhao Y and Cai SX (2010). Isolation, culture and differentiation into endothelial-like cells from rat bone marrow mesenchymal stem cells in vitro. Zhongguo Ying. Yong. Sheng Li Xue Za Zhi. 26: 60-65. 